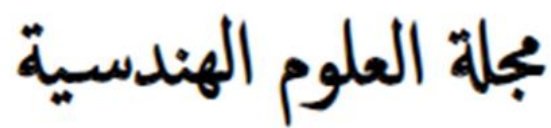

FES Journal of Engineering Sciences

\section{Utilization of Giad Steel Slag as Partial Replacement for Coarse Aggregates in Concrete}

\author{
Osama Daoud ${ }^{1}$ * and Muntasir Ibrahim ${ }^{2}$ \\ 1 Building and Road Research Institute, Khartoum, Sudan \\ 2 Civil Engineering Department, University of Khartoum, Khartoum, Sudan \\ * Corresponding author: Osama Daoud (e-mail: eng.osama72@yahoo.com).
}

Article history: Received 14 March 2020, Received in revised form 4 November 2020, Accepted 11 November 2020

\begin{abstract}
This research paper focuses on the possibility of utilization of Giad electric arc furnace slag (GEAFS) as a partial replacement for coarse aggregates in concrete, without compromising on its workability and strength. The electric arc furnace slag is a waste product from the steel manufacturing which may be used as partial replacement of coarse aggregates in concrete. This paper presents an experimental study on fresh and hardened properties of concrete containing steel slag aggregates. Slump, as well as strength properties of concrete prepared with natural coarse aggregate, partially replaced by the GEAFS in different proportions varying from $25 \%, 50 \%$ and $75 \%$. The GEAFS concrete shows marginal decrease in slump for the further replacement. Compressive, split and Flexural strength of the GEAFS concrete have been increased for the GEAFS addition. Highest compressive, tensile and flexural strength have been achieved by the mix containing $50 \%$ GEAFS coarse aggregates. Using of steel slag will result in decrease of waste landfilling, and improving environmental condition.
\end{abstract}

Keywords: Electric Arc Furnace Steel Slag, Coarse Aggregate, Compressive strength, Split tensile strength, Flexural strength.

\section{INTRODUCTION}

Seventy percent of the volume of concrete is occupied by aggregate, so the quality of aggregate is important. Not only the aggregates may limit the strength of concrete, as aggregate with undesirable properties cannot produce strong concrete, but the properties of aggregates greatly affect the durability and structural performance of concrete [1].

Solid wastes in steel industry are one of the environmental challenges which need to be solved. Reusing of this wastes in concrete is one of the solutions, to a re-use of recycled materials, avoiding their landfilling and thus has environmental benefit [2].

For economic reasons aggregate is originally viewed as an inert material dispersed largely throughout the cement paste. It is possible, however, to take an opposite view and look onto aggregate as a building material connected into a cohesive whole by means of the cement paste, in a manner similar to masonry construction. In fact, aggregates are not truly inert and their physical, thermal, and sometimes also chemical properties influence the performance of concrete [1].

Steel slag is an industrial by-product obtained during melting of steel scrap from the impurities and fluxing agents, which form the liquid slag floating over the electrical arc furnaces (EAF) [3].

Steel slag is defined as a non-metallic product, consisting essentially of calcium silicates and ferrites combined with fused oxides of aluminum, manganese, calcium and magnesium that are developed simultaneously with steel in basic oxygen, electric arc furnaces.[4]

There is a need to find a method that can recycle slag as a more highly valued material due to the fact that the annual world production of slag is 3.2 billion tons [5]. The EAF slag still has lower 
economic benefit than blast furnace slag because steel making plants typically do not have specialized quenching facilities [6].

Accordingly, a number of researches have focused mainly on the use of aggregates coming from products of steel and iron producing processes [6][7][8].

A series of recent studies have indicated that recycling of the EAFS slag as aggregate in concrete proved to be an economical and environmentally friendly solution and due to appropriate physical and mechanical characteristics. It seems that utilization of the EAFS slag as aggregate in concrete has advantages compared to dolomite aggregate and it can make high and ultra-high strength concrete [3][9].

Results of the experiments which are carried out on hardened concrete, indicated that using of $66.67 \%$ as a replacement percentage of the EAFS slag to the natural coarse aggregate achieved the highest values of compressive strength, indirect tensile strength, flexural strength and modulus of elasticity in mixes with and without silica fume[3].

Previous research [3] showed that the use of the EAFS without silica fume reduced the workability of concrete. This was due to that the surface texture, shape and porosity of the EAFS slag aggregates. The mixes without silica fume lacked mobility and hence resulted in low slump values. On the other hand, it can be noticed that improved values of slump were obtained when adding silica fume. Increasing the replacement ratio increased the slump value in mixes contained silica fume.

Local studies, have concluded that the steel slag can be considered reasonable alternative source of aggregates for concrete asphalt mixture production[10], [11] used local steel slag as partial replacement of fine aggregates and found that the compressive strength was increased, [12] used local steel slag as partial replacement for coarse aggregates and found that the consistence of concrete does not change because of addition of steel slag, compressive strength was increased by $11.7 \%$ from concrete containing $50 \%$ steel slag. Although [13] used Giad arc furnace slag as partial replacement for cement in mortar mixes and found that it has acceptable chemical and physical qualities when compared with the standards.

\section{MATERIAL AND METHODS}

\section{A. Cement}

The cement used in this study for casting all specimens was Ordinary Portland Cement produced by Al-Shamal cement Co. Grade 42.5 conforming to BS EN 197-1:2000.Its physical properties are listed in Table I.

\section{B. Fine Aggregate (FA)}

The sand used in this study for casting all specimens was locally river sand. Specific gravity and water absorption were $(2.59,2.1 \%)$ according to BS EN 1097-6:2000. Sieve analysis was investigated as per BS EN 933-1 and particle size distribution was within the limits requirement that have been given in BS 882 (1992).

\section{Coarse Aggregate (NCA)}

A locally rounded natural aggregate was used with $20 \mathrm{~mm}$ maximum size. Specific gravity and water absorption were $(2.64,0.77 \%)$ according to BS EN 1097-6:2000. Sieve analysis was investigated as per BS EN 933-1. Particle size distribution was within the limits requirement that have been given in BS 882 (1992). Crushing value shown in Table II was determined as per BS 812: Part110: 1990.

D. Steel Slag Aggregate (GEAFS)

EAFS aggregates obtained from Giad Industrial City. The GEAFS aggregates sample was porous rough texture with angular shape and was black in color see Fig.1, its chemical composition is listed in Table III, the specimen has a large amount of Ferric Oxide and that may because of the production process. Water absorption and specific gravity of GEAFS evaluated according to BS EN 1097-6:2000, aggregate crushing value test performed according to BS 812: Part 110: 1990, the GEAFS aggregates crushing value is $35.37 \%$, it within the BS 882 limit (45\%), these physical properties are listed in Table II.

\section{MIX PROPORTION}

Four concrete mixes were prepared, one of which was a reference concrete mix made using natural aggregates without adding EAFS 
aggregate as shown in Table IV, and the other three mixes had the same proportion of fine aggregate and cement with different replacement percentages of steel slag aggregates as shown in Table V.

Table I: physical properties of cement

\begin{tabular}{c|c}
\hline \hline PROPERTIES & VALUES \\
\hline Consistency & $25 \%$ \\
\hline Initial setting time & $135 \mathrm{~min}$ \\
\hline Final setting time & $208 \mathrm{~min}$ \\
\hline Two days strength & $\mathrm{N} / \mathrm{mm}^{2}$ \\
\hline \hline
\end{tabular}

TABLE II: AGGREGATES PHYSICAL PROPERTIES

\begin{tabular}{c|c|c}
\hline \hline Properties & NCA & GEAFS \\
\hline Specific gravity & 2.64 & 2.81 \\
\hline Water absorption & $0.77 \%$ & $1.38 \%$ \\
\hline Crushing value & $22.34 \%$ & $35.37 \%$ \\
\hline \hline
\end{tabular}

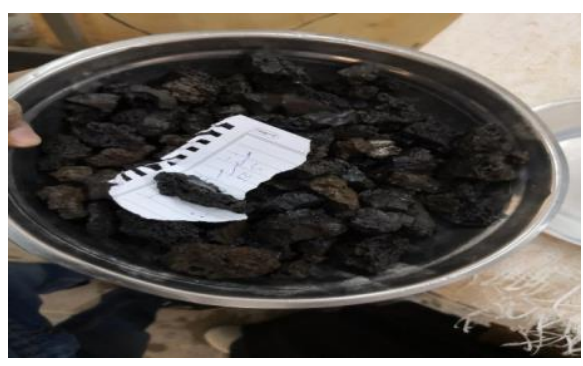

FIG.1. GEAFS SAMPLE

TABLE III: GEAFS CHEMICAL COMPOSITION

\begin{tabular}{c|c}
\hline \hline ELEMENT & RESULT \% \\
\hline SO3 & 0.103 \\
\hline SIO2 & 46.6 \\
\hline AL2O3 & 6.92 \\
\hline FE2O3 & 32.29 \\
\hline MNO & 3.492 \\
\hline CAO & 16.580 \\
\hline MGO & 7.623 \\
\hline
\end{tabular}

TABLE IV: REFERENCE CONCRETE MIX PROPORTION

\begin{tabular}{|c|c|c|c|}
\hline INGREDIENTS & \multicolumn{3}{|c|}{ AMOUNT $\left(\mathrm{KG} / \mathbf{m}^{\mathbf{3}}\right)$} \\
\hline FREE WATER & \multicolumn{3}{|c|}{195} \\
\hline CEMENT & \multicolumn{3}{|c|}{365.17} \\
\hline FINE AGGREGATE (FA ) & \multicolumn{3}{|c|}{781.52} \\
\hline $\begin{array}{l}\text { NATURAL COARSE AGGREGATE } \\
(\mathrm{NCA}) \\
\end{array}$ & \multicolumn{3}{|c|}{1038.46} \\
\hline \multicolumn{4}{|c|}{ TABLE V: GEAFS AGGREGATES CONCRETE MIX PROPORTION } \\
\hline Mix & $25 \%$ & $50 \%$ & $75 \%$ \\
\hline FREE WATER $\left(\right.$ KG $\left./ \boldsymbol{m}^{3}\right)$ & 195 & 195 & 195 \\
\hline $\operatorname{Cement}\left(\mathrm{KG} / \boldsymbol{m}^{3}\right)$ & 365.17 & 365.17 & 365.17 \\
\hline $\mathrm{FA}\left(\mathrm{KG} / \boldsymbol{m}^{3}\right)$ & 781.52 & 781.52 & 781.52 \\
\hline $\operatorname{NCA}\left(\mathrm{KG} / \boldsymbol{m}^{3}\right)$ & 259.615 & 519.23 & 778.845 \\
\hline $\operatorname{GEAFS}\left(\mathrm{KG} / \boldsymbol{m}^{3}\right)$ & 778.845 & 519.23 & 259.615 \\
\hline
\end{tabular}

\section{RESULTS AND DISCUSSION}

For all the concrete mixes, Slump, compressive, split tensile and flexural strengths were determined at the end of 7 and 28 days. The results were obtained by experimental and discussed as follows:

\section{A. Slump}

Slump test was carried out according to BS EN 12350-2. As can be seen in Fig.2, The GEAFS mixture shows relatively lower slump comparing with the reference mix, the addition of the GEAFS aggregates decrease the slump, the lower slump of concretes made with GEAFS aggregates is mostly related to the angular shape and to the rough texture of GEAFS aggregates.

\section{B. Density}

Fig.3. shows hardened concrete density according to BS EN 12390-7:2019, density of concrete mixes with GEAFS aggregates is higher than the reference mix. That because of the higher specific gravity value of GEAFS aggregates comparing to that of NCA.

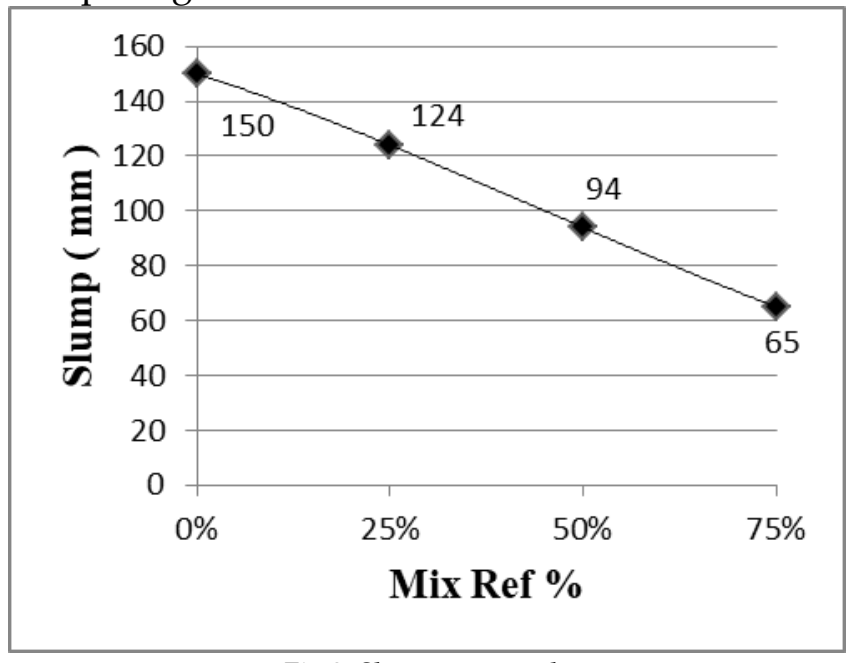

Fig.2. Slump test results

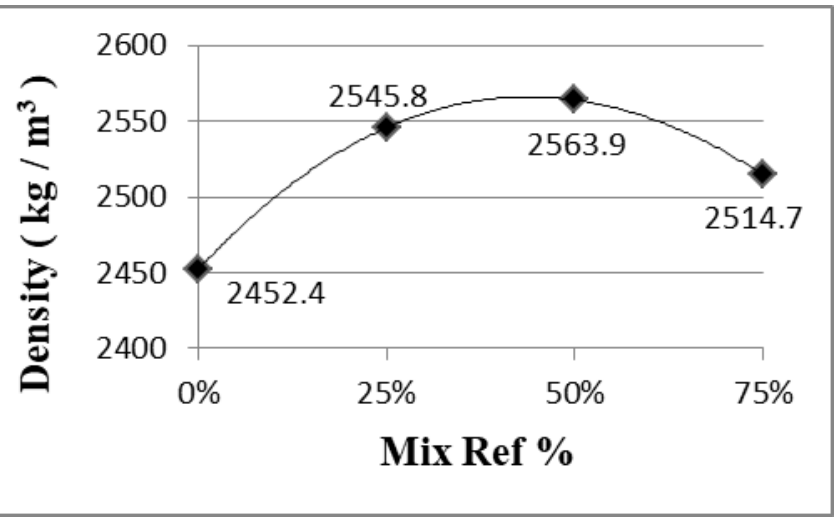

Fig.3. Hardened concrete density

\section{Compressive Strength}

The compressive strength was measured according to BS EN 12390-3:2019 at 7 and 28 days and the results were discussed as follows: 
A. 7 days Compressive Strength

The compressive strength at 7 days after curing of mixes with four different percentages of adding GEAFS aggregates are given in Fig.4. It can be seen that the compressive strength of GEAFS concrete mixes are higher than the reference mix. The angular shape and the rough texture of GEAFS aggregates can also be responsible for the improvement of the compressive strength.

\section{B. 28 days Compressive Strength}

The compressive strength at 28 days after curing of mixes with four different percentages of adding GEAFS aggregates are given in Fig.5. It can be seen that the compressive strength of $50 \%$ GEAFS concrete mix is higher than the other three mixes. And this is agreed with previous study[3]. The higher density of GEAFS aggregates mix can also be responsible for the improvement of the compressive strength. Fig.6. shows failure surface of $75 \%$ mix cube, some of the aggregates are fractured at the mix of $75 \%$ while the cracks developed at the paste-aggregates interface at the failure surface of $50 \%$ mix cube because of the lesser crushing value of GEAFS aggregates and that can be explain the higher compressive strength of $50 \%$ mix.

\section{Split Tensile Strength}

The split-cylinder tensile strength was measured according to BS EN 12390-6:2019 at 7 and 28 days and the results were discussed as follows:

\section{A. 7 days Split Tensile Strength}

The split-cylinder tensile strength 7 days after curing is shown in Fig.7. The trend of the tensile strength development was approximately similar to that of the compressive strength development. The split-cylinder tensile strength of GEAFS concrete mixes are higher than the reference mix.

\section{B. 28 days Split Tensile Strength}

Fig.8. shows the variation of split tensile strength with different GEAFS aggregates replacement percentages it is observed that the split-cylinder tensile strength of GEAFS concrete mixes are higher than the reference mix. Fig.9. shows failure surface of $75 \%$ mix cylinder.
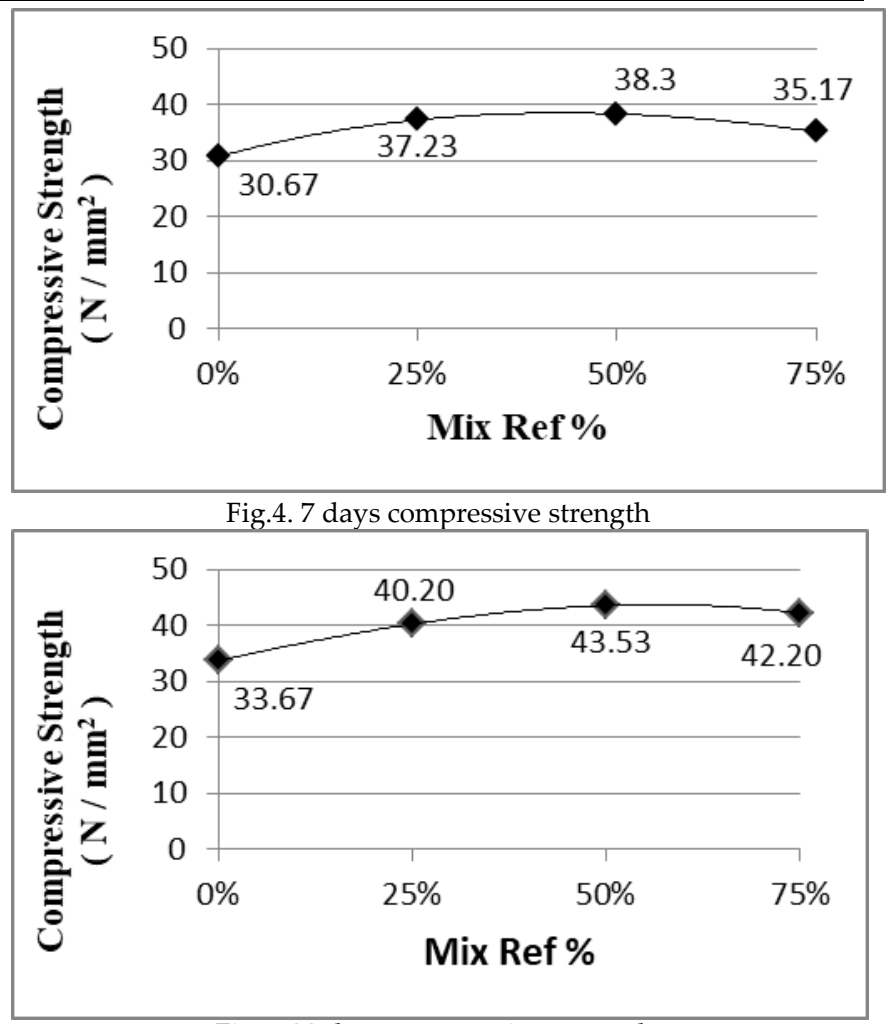

Fig.5. 28 days compressive strength

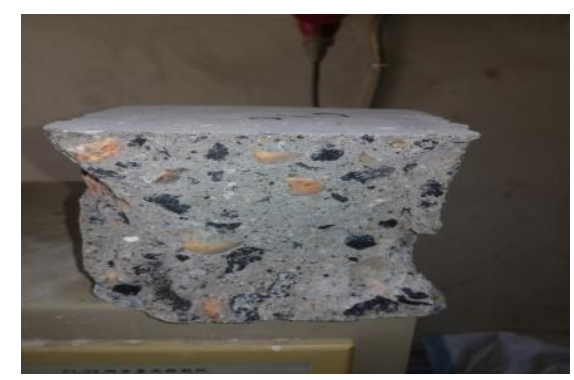

Fig.6. Failure surface of cube mix contain75 \% GEAFS.

\section{E. Flexural Strength}

The Flexural Strength was measured according to BS EN 12390-5:2019 after 28 days of curing and the results are shown in Fig.10, it can be seen that the high percentages of GEAFS aggregates significantly improve the flexural strength.

\section{CONCLUSIONS}

In this paper properties of steel slag were experimentally studied to be used as aggregate in normal concrete. According to the results of conducted experiments, the followings are concluded:

A. Results of the experiments carried out on fresh concrete, indicate that the GEAFS slag concretes decrease consistence.

Results of the experiments carried out on hardened concrete; indicate that the maximum value of compressive, tensile and flexural 
strengths at 7 and 28 days was achieved at about $50 \%$ GEAFS concrete mix.

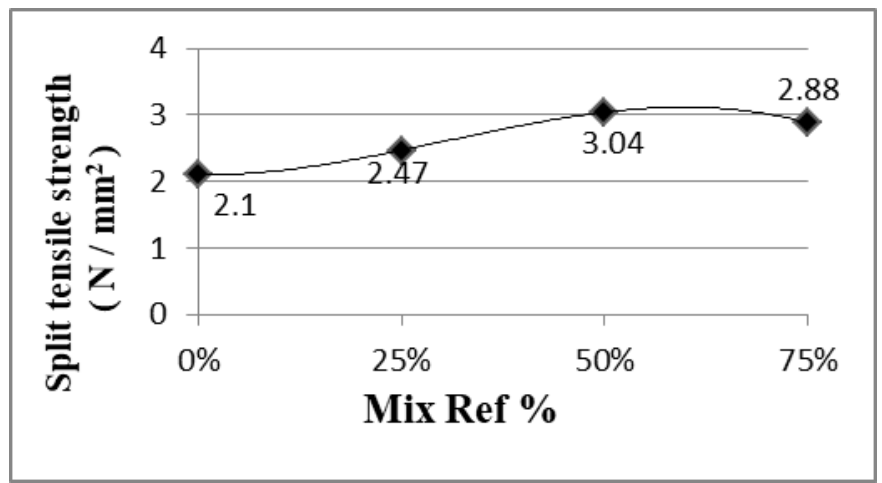

Fig.7. 7 days split tensile strength

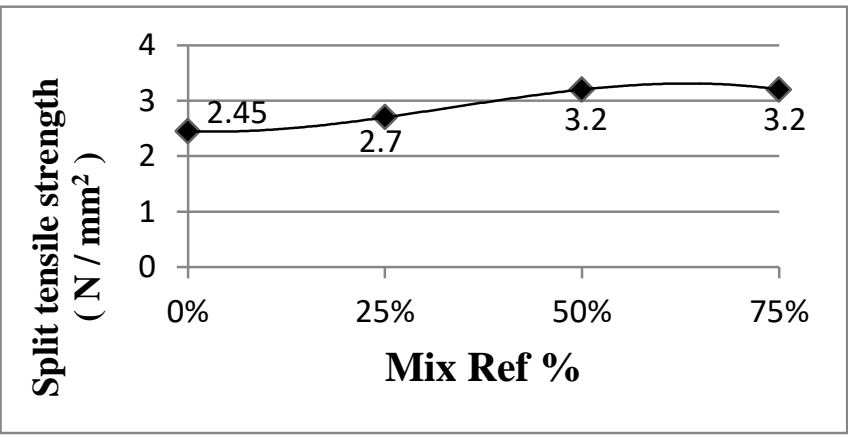

Fig.8. 28 days split tensile strength

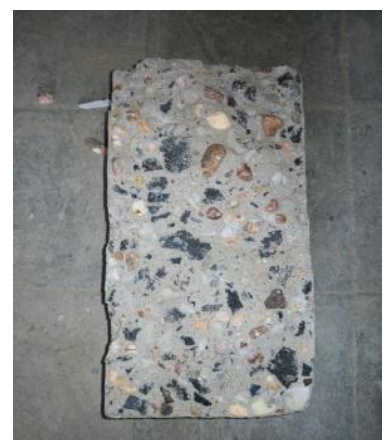

Fig.9. Failure surface of cylinder mix contain $75 \%$ GEAFS.

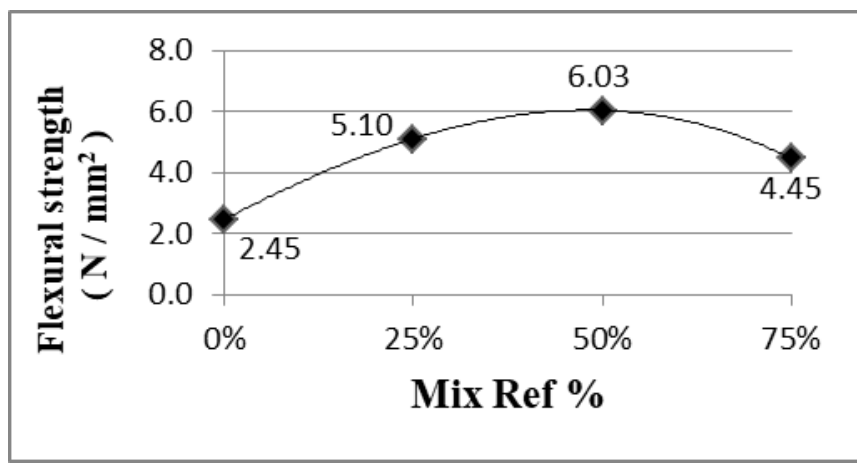

Fig.10. 28 days flexural strength

B. Recycling steel slag as aggregate in concrete not only improves mechanical properties of concrete, but also helps the surrounding environment to be protected against its severe deposit problems and avoiding their landfilling.
C. Further experiments would be necessary to evaluate the effects of adding GEAFS slag on durability of concrete.

\section{ACKNOWLEDGMENT}

My ultimate thanks Compassionate and Merciful Allah.

My deepest thanks to those who have enriched my research, with valuable information and data.

\section{REFERENCES}

[1] A. Neville, Properties of concret- 5th Edition.Pearson Education Limited 2011.

[2] I. Arribas, A. Santamaría, E. Ruiz, V. Ortega-López, and J. M. Manso, "Electric arc furnace slag and its use in hydraulic concrete," Constr. Build. Mater., vol. 90, pp. 68-79, 2015.

[3] M. A. Khafaga.,et al., "Properties of High Strength Concrete Containing," Gradjevinar., vol. 42, no. 3, pp. 582-608, 2014.

[4] W. S. DOT, “WSDOT Strategies Regarding Use of Steel Slag Aggregate in Pavements A Report to the State Legislature In Response to 2ESHB 1299 Prepared by : Washington State DOT Construction Division Pavements Office November 2015," 2015.

[5] E. E. Hekal, S. A. Abo-El-Enein, S. A. El-Korashy, G. M. Megahed, and T. M. El-Sayed, "Hydration characteristics of Portland cement - Electric arc furnace slag blends," HBRC J., vol. 9, no. 2, pp. 118-124, 2013.

[6] F. Faleschini, K. Brunelli, M. A. Zanini, M. Dabalà, and C. Pellegrino, "Electric Arc Furnace Slag as Coarse Recycled Aggregate for Concrete Production," J. Sustain. Metall., vol. 2, no. 1, pp. 44-50, 2016

[7] R. Alizadeh, M. Chini, P. Ghods, M. Hoseini, S. Montazer and M. Shekarchi, "Utilization of Electric Arc Furnace Slag as Aggregates in Concrete Environmental Issue," 6th Int Conf. Recent Adv. Concr. Technol., vol. 1, June 2003, pp. 451-464, 2003

[8] I. Papayianni and E. Anastasiou, "Utilization of Electric Arc Furnace Steel Slags in Concrete Products," in 6th European Slag Conference, October 2010, pp. 20-22, 2010.

[9] A. Sekaran, M. Palaniswamy, and S. Balaraju, "A Study on Suitability of EAF Oxidizing Slag in Concrete: An Eco-Friendly and Sustainable Replacement for Natural Coarse Aggregate," Sci. World J., vol. 1, pp. 21-32. 2015.

[10] Zumrawi, M. M. 2016. Experimental study of steel slag used as aggregate in asphalt mixture.

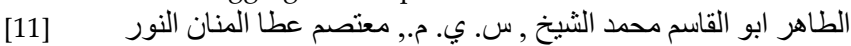

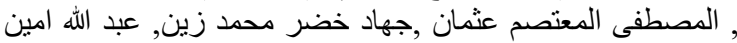

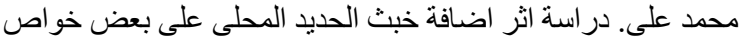

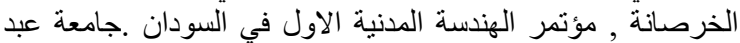
اللطيف الحمد , مروي. 2016

[12] Y. Hummaida , M. Agaeb , Use of Steel Slag as Partial Replacement for Coarse Aggregates in Concrete.

[13] O. Daoud, S. Al-malek, " Characterization and Evaluation of Giad Arc Furnace Slag as Partial Replacement for Cement in Mortar Mixes, "Journal of Building and Road Research., vol. 20, pp. 29-47. 2017. 